\title{
Implementation of Community Policing Policy in Creating General Security and Order in The City of Bandung, West Java Province
}

\author{
Y. Prapto, \\ Markas Besar Polri \\ Ermaya Suradinata, \\ Institut Pemerintahan Dalam Negeri \\ Deti Mulyati, \\ Institut Pemerintahan Dalam Negeri \\ Irwan Thahir, \\ Institut Pemerintahan Dalam Negeri
}

Received: June 4, 2019 Accepted: July 3, 2019 Online published: July 8, 2019

doi:10.5296/jpag.v9i2.14809 URL: https://doi.org/10.5296/jpag.v9i2.14809

\begin{abstract}
The implementation of community policing policies in creating security and public order in the city of Bandung was revealed according to the Von Meter and Von Horn public policy implementation models, there are six variables that shape the relationship between policy and performance. The implementation of the policy must be able to adjust the condition and situation of the object from the implementation of policies adjusted to the dynamics that occur in the field. There is a finding on the factor that hinders the implementation of community policing policies, including the low quality of the human resources that play the role, inadequate funding resources, lack of community policing policy and the lack of local culture empowerment. A new concept obtained so that the implementation of community policing policies in realizing security and order in the city of Bandung can be carried out effectively, so the author found the OK PRAPTO Model, which is a normative model that
\end{abstract}


yields result according to ASOCA analysis to enable the implementation of the community policing policy in the city of Bandung.

Keywords: Implementation of community policing policies, security and public order

\section{Introduction}

Some functions of government that are very important and of strategic value for the effective implementation of government in realizing the goal of establishing a State Government as stated in the Preamble of the 1945 Constitution are protection functions, law enforcement functions, service functions and functions of community empowerment. The implementation of the four functions of government is inherent in the duties and functions of the police (Polri). The duties and functions of the National Police are regulated in the state policy that regulates the Police.

The considerations that underlie the issuance of State policies governing the Police are contained in Law No. 2 of 2002 concerning the Police which explained that the maintenance of internal security through efforts to carry out police functions which include the maintenance of security and public order, law enforcement, protection, protection, and community service were carried out by the Republic of Indonesia National Police as a tool of the community uphold human rights. In order to carry out police functions effectively in realizing security and public order, the Chief of Police issued a policy in the form of Head of the Indonesian National Police Regulation Number 3 of 2015 which regulates Community Policing. The considerations that underlie the issuance of the policy of the National Police Chief are that to carry out the tasks of the Indonesian National Police in maintaining public order and security, upholding the law, providing protection, protection and service to the community, the ability of police members to implement community policing strategies to build partnerships and cooperation by involving the community to maintain security and order in their environment. Furthermore, the Regulation of the Head of the National Police of the Republic of Indonesia Number 3 of 2015 Article 2 describes the purpose of the Polmas regulation which includes: a). as a guideline for Polri members in carrying out community policing activities effectively and efficiently; and b). the realization of Polri and community partnerships based on a mutual agreement to deal with social issues that can disrupt the Kamtibmas to create security, order, and peace.

The implementation of security will not succeed, if it is only carried out by the National Police, therefore there must be a joint effort involving the community in dealing with the issues of Kamtibmas. Kamtibmas itself is a view that refers to the importance of Polri's partnership with the community, where its implementation refers to the potential and participation of the community, especially the potential and participation of institutions that have become partners of the National Police such as the Polri and Community Partnership Forum (FKPM). This partnership is certainly actualized in the implementation of the duties and functions of the National Police in the regions, including the implementation of the duties and functions of the National Police in the city of Bandung, West Java Province. On the other hand, Bandung City also has problems such as occurring at population density. The increase in population, besides due to fertility and mortality also due to high urbanization as explained 
in the Central Bureau of Statistics (BPS) year (2016) states that the migration into Bandung is the highest in West Java. The high increase in population caused other problems in the city of Bandung such as acts of criminalization that disrupted security and order. This is confirmed by Topo S \& Eva A. S, (2001: 65) which states that the development of areas with high crime rates is always related to the disintegration of conventional values caused by rapid industrialization, increased immigration, and urbanization.

The crime rate in Bandung City in 2017 decreased by 41 percent compared to 2016. Based on the annual analysis and evaluation (Anev) data from Bandung Police Office, the total crime crimes in 2017 were recorded at 3,233 cases. This number has decreased compared to 2016 which reached 3,546 cases. The Bandung City Kamtibmas report was quite positive because it dropped by almost 9.1 percent. Criminal cases included in the $\mathrm{C} 3$ category (stolen, curated and careless) experienced a significant decline compared to 2016. For cases of stealing, the number decreased from 423 cases in 2016 to 76 cases in 2017 or decreased 82.03 percent. In addition, in the case of curas, it decreased from 209 cases to 54 cases or decreased by 74.16 percent. Likewise, for the case of two-wheeler motor vehicles decreased from 460 cases to 133 cases or decreased 71.09 percent and four-wheeled vehicles from 51 cases in 2016 to 14 cases in 2017 or decreased 72.55 percent.

Although criminal acts and community disturbances have decreased, if seen as a whole the number of crimes in the city of Bandung is still quite high, this is also reported by Republika, which states that in 2017 criminal cases in West Java were in the city of Bandung, this shows that the crime rate in the city of Bandung as a whole cannot be said to have experienced a significant decline. Furthermore, from January to July 2018 criminal acts and disturbances in the city of Bandung were dominated by curas, curses, and caresses (C3) which mostly occurred after post-fasting or during long holidays with 270 cases.

At the technical level, the implementation of the community policing program that has been implemented in the city of Bandung seems to have not been able to run optimally. Although reports of public disruption and criminal offenses according to the police tend to decline, in reality, this is not the case. The presence of several criminal cases in the city of Bandung, such as street crime (mugging, breakdown) and community feuds which occurred yesterday between online motorcycle taxis and base motorcycle taxis are examples of real conditions that describe if the community policing has not been optimally implemented.

Referring to the not yet optimal decrease in the quantity of Kamtibum disruption in the City of Bandung, West Java Province, the interesting question to be answered factually is "How is the implementation of community policing policies in creating security and public order in the city of Bandung, West Java Province? Compared to other areas in West Java, this is not optimal. This can be seen from the statement of the West Java Regional Police Chief, Inspector General Agung Budi Maryoto, who explained that the highest crime rate in 2017 is in the jurisdiction of Polrestabes Bandung with 3,072 cases, both Bogor police and 3,031 cases and third Karawang police station 2,687 cases. (West Java Regional Police Chief, Inspector General of Police Agung Budi Maryoto at the West Java Regional Police Headquarters in Bandung, Friday (29/12) republika.co.id accessed June 5, 2018). In addition, 
the level of general disturbances and crime rates in the city of Bandung has not shown a significant decline even though the implementation of community policing has not been able to significantly reduce the level of disturbance and crime in Bandung. This condition confirms that the Kamtibum development in Bandung has not run optimally so that there needs to be an increase in the perspective of the implementation of community policing policies in Bandung as follows: The level of community participation in the implementation of Community Policing policies tends to decrease due to the development of individualism so that prevention of security and public order disturbances has not been optimally implemented; The implementation of Community Policing in utilizing the local culture of Bandung residents to prevent disturbances in security and public order is not optimal and the slow dissemination of information and coordination in the implementation of the Community Policing policy has made public administration services to the community not yet qualified. Based on the background and identification of the problems above, the formulation of the problem in this study is 1) How is the implementation of the Community Policing policy in creating security and public order in the City of Bandung? 2) What factors influence the implementation of Community Policing policies in creating security and public order in the City of Bandung? 3) What model of implementation of ideal policies is considered most appropriate in the implementation of the policy of Community Policing in creating security and public order in the City of Bandung?

\section{Theoretical Framework}

\section{Implementation of Public Policy and Community Policing}

Because the implementation of public policy is included in the mechanism of administering public administration or say government administration, then inevitably the understanding of public implementation cannot be separated from the perspective of understanding public administration. This thinking refers to the opinion of Sharkansky (1973: 3) who said "A definition of policy that fits many of its uses by political scientists is: the important activities of the government. The activity is "important" if it involves - or propositions to be involved thus the implementation of public policy is not only related to the use of a number of resources such as budgetary resources and resources. environmental power; but it also involves the interests of many people. In this perspective, Sharkansky also said, "The policy process includes the formulation, approvals, and implementation of government programs." In the implementation of this government program, activities of interrelationships or collaboration between parties such as the integration of various wisdom resources are established. The Von Meter model and Von Horn: Von Meter and Von Horn (1975: 462) designed a policy implementation model by saying that there are six variables that form the relationship between wisdom and performance. According to Von Meter and Von Horn:

This model not only specifies the relationships between the independent variables and the ultimate dependent variable of interest but also makes explicit the relationships among the independent variables. The linkages included implicitly represent hypotheses which could be tested empirically, assuming that satisfactory indicators could 'be constructed and appropriate data collected. By approaching the problem in this manner, there is a greater promise for 
elucidating the processes whereby policy decisions are carried out than simply by correlating. independent and dependent variables in a relatively unthinking fashion (Van Meter and Asher, 1973). The model has been constructed on the basis of the three bodies of literature cited above, as well as the authors' own research and intuitions about the implementation process.

The policy implementation model proposed by Von Meter and Von Horn not only determines the relationship between the independent variable and the main dependent variable but also makes explicit the relationship between the independent variables. These linkages are hypotheses that can be empirically tested, assuming that indicators can be built and appropriate data can be collected. Approach the problem in this way, there is a greater opportunity to explain the process by which the policy decision is made compared to connecting. The relationship between variables in the Von Meter and Von Horn policy implementation models is illustrated below:

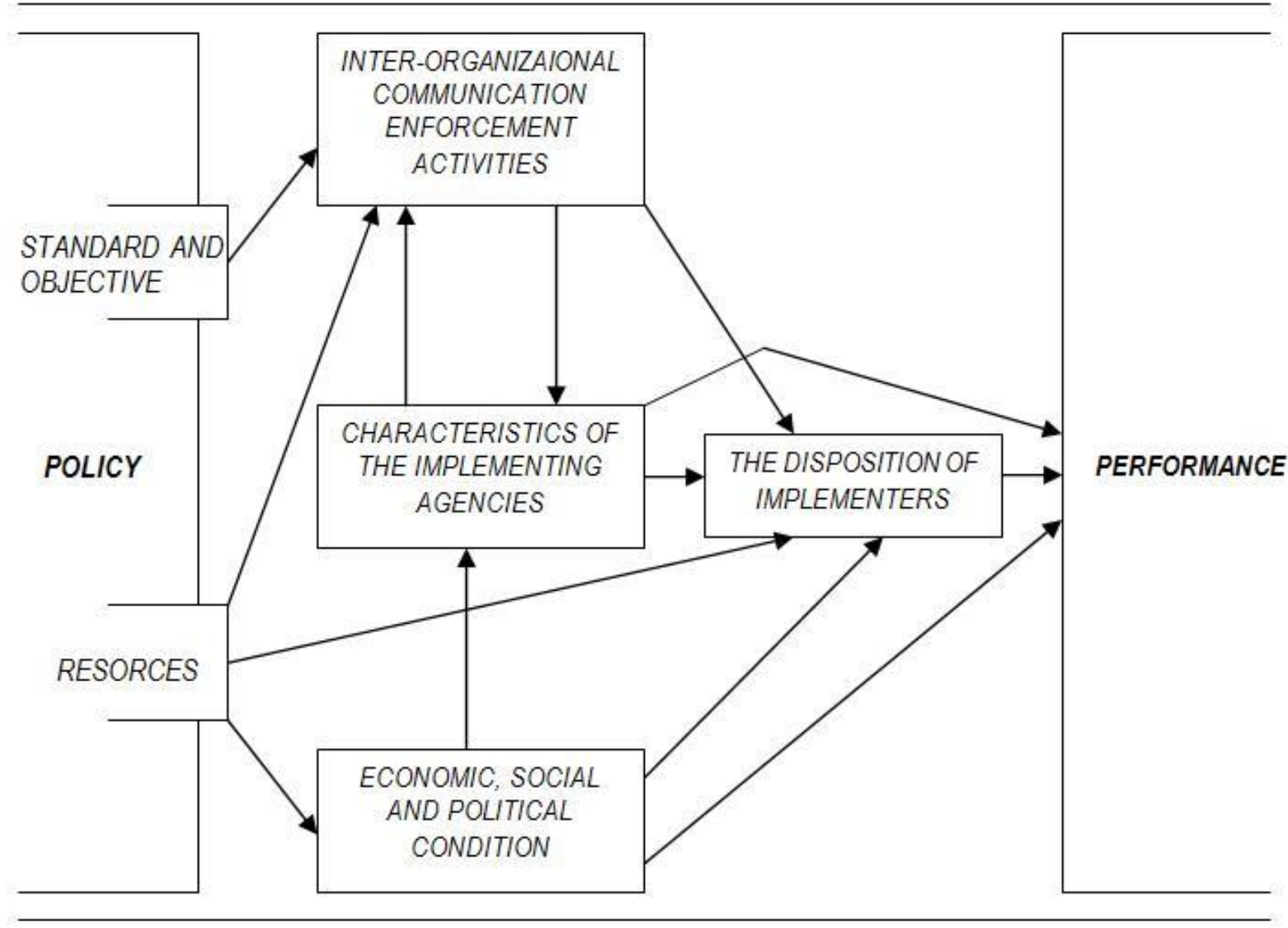

Figure 1. A model of the policy implementation process of the Van Meter \& Van Horn Source: Van Meter dan Van Horn, 1975: 462.

Hill and Hupe (2002: 45) explain the model of policy implementation according to the following Von Meter and Von Horn:

Van Meter and Van Horn go on to suggest a model in which six variables are linked dynamically to the production of an outcome 'performance'. The six variables (surely are in 
fact clusters of variables) are:

1. Policy standard and objective, which elaborate on the overall goals of the policy decision ... to provide concrete and more specific standards for assessing performance;

2. The resources and incentives made available;

3. The quality of inter-organizational relationships (we find in their discussions of this, as in so much of the American literature on implementation, an extensive discussion of aspects of federalism);

4. The characteristics of the implementation agencies, including issues like organizational control but also, going back surely to inter-organizational issues, the agency's formal and informal linkages with the "policy-making" or "policy-enforcing" body;

5. The economic, social and political environment; and

6. The disposition or response of the implementers, involving three elements: their cognition (comprehension, understanding) of the policy, the direction of their response to it (acceptance, neutrality, rejection) and the intensity of that response.

Regarding the Policy Standards and Objectives variable, Van Meter and Van Horn (1975: 464) explain:

Given our primary interest in the factors that determine the performance of the policy, the identification of performance indicators is a crucial stage in the analysis. Essentially, the performance indicators assess the extent to which the policy's standards and objectives are realized. Standards and objectives elaborate on the overall goals. of the policy decision. They move beyond the generalities of the legislative document to provide concrete and more specific standards for assessing program performance. These standards and objectives are self-evident and easily measurable in some cases. To ascertain whether implementation has been successful, one must determine the number of jobs that have been created, the identity of those who have been hired, and the progress on the related public works projects.

In the view of Von Meter and Von Horn, identification of performance indicators is an important stage in the analysis. Basically, performance indicators assess the extent to which the standards of policy and objectives are realized. Standards and objectives are complicated at the overall goal. policy decision. They move beyond the generalization of legislative documents to provide more specific standards for assessing program performance. The reason for choosing Von Meter and Von Horn's public policy implementation model is because the model is considered appropriate to explore and analyze the phenomenon of the implementation of Community Policing policies in creating security and public order in the city of Bandung. This reason refers to the concept of understanding as follows:

1. Standards and Objectives (objectives and standardization of Polmas policies) can be directed to dissecting Perkap Number 3 of 2015 concerning Community Policing (concerning principles, philosophy, functions, and objectives of Community Policing); 
2. Policy Resources and Incentives (incentives and policy resources) can be directed to dissect incentives and support resources for the implementation of the functions and activities of the National Police and Community Partnership Forum, hereinafter abbreviated as FKPM as a vehicle of communication between the National Police and the community carried out on the basis of mutual agreement in the framework to discuss Kamtibmas issues and social problems that need to be solved together in order to create conditions that support the smooth operation of police functions and improve the quality of life of the community;

3. Interorganizational Communication and Enforcement Activities can be directed to dissect communication, coordination, and consultation as well as cooperation between FKPM and Polri, FKPM with the community, and FKPM with stakeholders.

4. The Characteristics of the Implementing Agencies can be directed at dissecting the authority, structure, duties, and functions of the FKPM in implementing Polmas policies;

5. Social, Economy and Political Conditions can be directed at dissecting the dynamic situations and conditions of social and cultural, socio-economic and socio-political life that have an impact on public security and order and their influence on the existence of FKPM;

6. The Disposition or Response of Implementors can be directed at dissecting deviation trends or responses from FKPM activists in implementing Polmas policies and activities in their environment.

\section{Community Policing}

Community Policing is an activity to invite the community through partnerships between members of the Indonesian National Police and the community to be able to identify issues of security and public order (Kamtibmas) in the environment and find solutions to these problems. Identification and problem-solving in the implementation of community policing policies are certainly related to the role of the police manager at a certain level. In this context, Lubans and Edgar (1979: 5) proposed the following concept of Policing by Objectives (Policing By Objectives $=$ PBO) that Policing by Objectives $(\mathrm{PBO})$ is a process of planning, executing and reviewing those activities of a police organization oriented toward specific desired results. PBO is adopted from a management process designed for uses in the private. According to Lubans and Edgar, Policing Based on Purpose (PBO) is a process of planning, implementing and reviewing the orientation of police organization activities towards achieving the desired results. PBO is adapted from process management designed for private organizations. Related to PBO, Lubans and Edgar (1979: 18) revealed:

Police managers have been recognized for some time that there is an incredible amount of untapped and lower rank used talent - traditional talent, tendered to waste management. The problem has not been disrupting discipline or undermining basic management prerogatives. PBO solves this problem. It is organized and structured means to control and use their services to the maximum use without sacrificing management.

In the view of Lubans and Edgar, police managers have admitted for some time that there are a number of extraordinary things from untapped and underutilized talents (members of the 


\section{MInstitute Macrothink $^{\text {Int }}$}

Journal of Public Administration and Governance

ISSN 2161-7104

2019, Vol. 9, No. 2

National Police) in the lower ranks - traditional talent, centralized management methods that tend to drain. The problem has long been that placing such talent can work for the good of the department without interrupting discipline or undermining the prerogative of basic management. PBO solves this problem. PBO provides an organized and structured means for subordinates to be involved in managing their own work and to place their talent for maximum use without sacrificing management control over departmental affairs. Related to talent or potential personnel, Lubans and Edgar (1979: 18) explained:

Most of this unused talent is put to work in the PBO planning process. Lower-level personnel has traditionally had important responsibilities in implementing departmental programs, but almost no role in the planning process that preceded the implementation. Planning in police organizations is usually highly centralized. It is common to find that a central planning office develops plans for the entire organization. In PBO, the planning function is carefully decentralized. Planning tasks are systematically assigned to the level within the police department best able to do each particular task. The result is that overall planning and policy-making becomes the responsibility of the police executive and his staff of middle managers, while detailed planning for individual units is assigned to the units which actually will carry out the plan.

According to Lubans and Edgar, most of these unused talents work in the Policing Based on Purpose (PBO) planning process. Low-level personnel traditionally have important responsibilities in implementing departmental programs, but there is almost no role in the planning process that precedes implementation. Planning in police organizations is usually very centralized. It is common to find that the central planning office develops plans for the entire organization. In PBO, planning functions are carefully decentralized. To eliminate the possibility of incomplete communication. PBO uses the "pin linking" process. At each step in the planning stage, two adjacent levels of the organization are always involved. Managers who participate in planning activities at one level are always included in subsequent planning at the next lower level. The six main steps of PBO are shown by Lubans and Edgar (1979: 23) below:

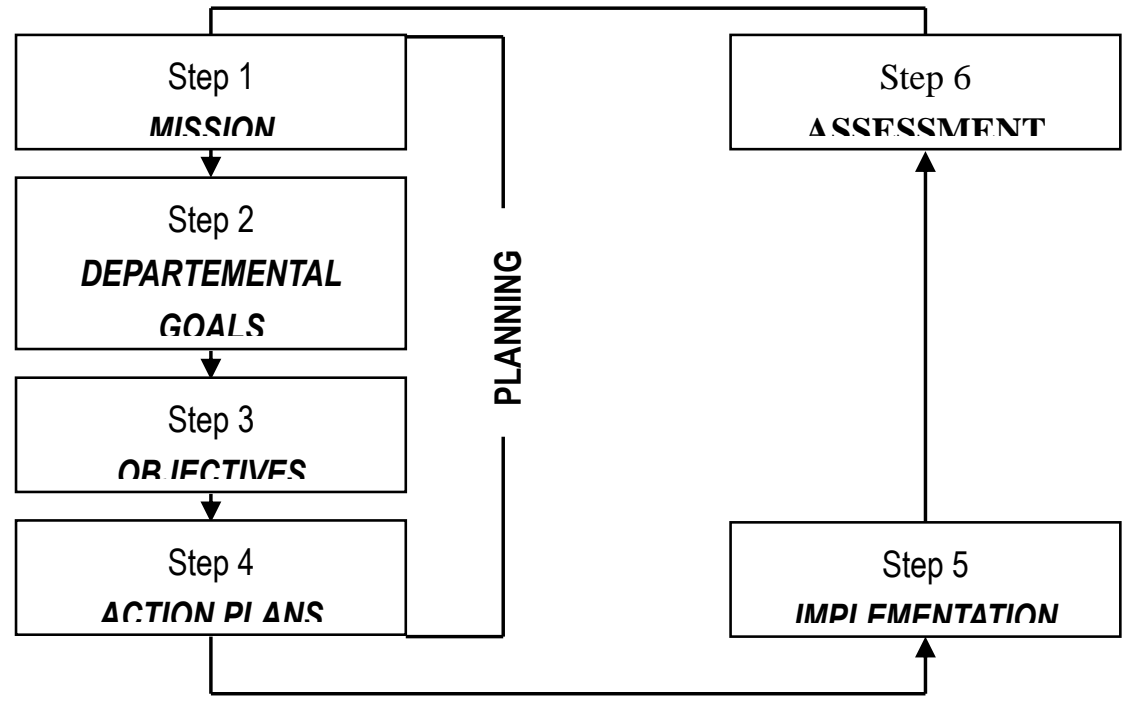


Figure 2. The Basic PBO Cycle

Source: Lubans dan Edgar, 1979:23

\section{Method}

The data sources in this study consist of secondary data sources and primary data sources. Secondary data sources include various books and documents and other sources of information. The primary data source is the resource person who became the research informant. From secondary data sources, secondary data types are obtained consisting of information concerning the object of research, namely: the implementation of community policing policies in creating security and public order in the city of Bandung; the theories needed to develop scientific insights in understanding the object and focus of research, and the selection of theories that are used as the theoretical foundation for the preparation of research concepts. The primary data sources obtained from the primary data type are needed to uncover and analyze the focus of the research according to the implementation model approach to the wisdom of the public Von Meter and Von Horn which consists of six variables and each variable with several questions consisting of 24 questions.

The twenty-four questions are then developed and adjusted to the position, role, competence or involvement of each research informant. The development and adjustment of each question in question are carried out to explore the depth of the object of research, the implementation of community policing policies in creating security and public order in the city of Bandung. The technique of determining research informants is the resource person who provides various information, information, and data regarding the phenomenon that is used as the object of study. The technique of determining someone to be a research informant is done according to the assessment of the position, competence or involvement in the process of implementing community policing policies in creating security and public order in the city of Bandung. In order to identify the resource person according to the assessment, a survey and consultation were conducted to several parties who were deemed to be willing to help. After a survey and consultation, the technical determination of research informants was carried out with the snowball technique.

The next stage in the research implementation of community policing policy in improving security and public order in the city of Bandung, West Java Province through internal and external thinking of the organization is by using ASOCA analysis so that it is expected to produce polmas implementation output in accordance with expectations based on the needs and abilities of the community and police carry out government functions in the field of security and order.

\section{Research Result and Discussion}

\section{Implementation of Community Policing Policy in Creating Public Security and Order in the City of Bandung}

a. Analysis of Policy Standards and Objectives

The police is an organization that has the main goal of realizing public safety, to provide a 
maximum sense of security and comfort to the community, of course, must adjust the implementation of the main tasks and functions of the Police with all the dynamics that occur in the community. The implementation of the main tasks and functions of the Police cannot be carried out by ignoring any developments that occur in the community, because the community is an object as well as a subject that simultaneously becomes the goal of the main tasks and functions of the Police as partners of the Police in order to achieve security and order. Based on the results of the interview it can be concluded that the purpose of community policing is a good partnership between the police and the community, besides that which is no less important is community policing can increase public awareness and concern for problems in their environment that have potential security and order disturbances. In line with this, according to Dye (in Dunn, 1981: 46) How the environment of policy processes accompanies a public policy shown in the following picture:

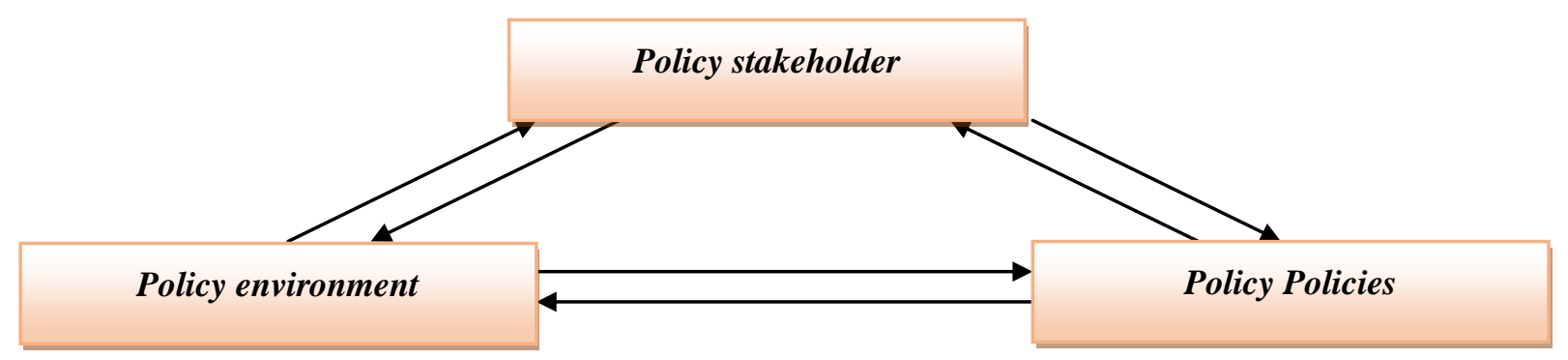

Figure 3. Parts of the system of Policy

Source: Dunn, 1981:46

The description of the policy system above shows insight into how the interrelation between the process of implementing public policy takes place and involves the interests of the parties.

b. Resource and Incentive Analysis

Related to the quality of Human Resources (HR) who play a role in community policing must still be improved because based on the findings in the field, it shows that the lack of maximum policing in the community is one of the reasons for the quality of human resources. The results of interviews with Respondents, argued about the quality of human resources who play a role in community policing as follows:

The quality of human resources who play a role in community policing has not been maximized with various obstacles including poor budget, human resource capacity, lack of infrastructure, a plurality of community stratification so that the training must adjust and this is quite troublesome minimal community support.

Financing resources are also one of the main aspects of supporting the success of Community Policing. It is inevitable that to sustain the implementation of public policy, financing resources must get serious attention because based on the findings in the field, the source of funding is one of the main causes of failure to implement a policy. According to Grindle 
(1980: 148) states that the implementation of effective public policy requires certain conditions. The policy implementation process can only be started if the objectives and objectives that were originally general have been detailed, action programs have been designed and a number of costs have been allocated to realize these goals and objectives.

c. Quality Analysis of Relationships between Agencies and Institutions

The use of IT in operational communication which was originally intended to increase the spread of information, in reality, did not work well. The aspect of cooperation between agencies and Polrestabes with the city government of Bandung as an element of supporting the implementation of Polmas has not been maximally utilized. Effective communication in the implementation of the policy is clearly needed because the communication function can clarify the contents of wisdom that must be understood and explained by each implementor. In terms of this communication, Edward III (2003: 19) said:

The first requirement for the implementation of wisdom is that those who must implement a decision must know what they must do. Policy decisions and implementation regulations must be transmitted to personnel right before they can be followed. Naturally, this communication requires accuracy, and communication must be accurately accepted by the implementor. Many obstacles lie in the communication transmission path in the implementation process, however, and obstacles.

Interferes with policy implementation. Thus the accuracy of communication in the policy implementation process becomes important.

\section{d. Analysis of Characteristics of Implementing Institutions}

Community policing is a party that is a mediator in the implementation of this restorative justice. Although in the police law and also in the Criminal Procedure Code there is no clear mention of the authority of the Police / Community Policing as a mediator in resolving a misdemeanor but the Criminal Code, the police law and the Republic of Indonesia National Police Chief Regulation No. 3 of 2015 concerning Community Police, said the police can act with their own judgment regulated in Article 17 Paragraph 1 letter e Regulation of the Head of the National Police of the Republic of Indonesia No. 3 of 2015 concerning Community Policing, here according to the Polmas assessment that a criminal case that has an attachment to a civil case, as well as its impact is not severe and is able to be resolved through a consensus mechanism, the Polmas consider the value of justice and the benefits of implementing a restorative justice approach to resolve case.

At the level of implementation, commitment and capability of implementing Polmas are limited to carrying out tasks. This condition, as conveyed by IPTU, Sulistyowati, stated that the Polmas Commitment up to now was only limited to carrying out the task because there was no full support from the leadership element. This means that members of the police in carrying out are more committed to carrying out the commands of the leadership when compared to their commitment to achieving program objectives.

e. Economic, Social and Political Environment Analysis 
The increasingly complex situation of social conditions in the city of Bandung also had a significant influence on the increase in legal violations and security disturbances in the city of Bandung. This has a relationship with economic conditions because of the increasingly complex social conditions characterized by the occurrence of gaps that are quite far between the classes of society can trigger legal violations and disruption of order. This was conveyed by the Respondent in his interview stating that: increasingly difficult economic conditions are often the dominant factor in triggering violations in the community such as theft in residential areas and in shopping areas.

The explanation is well-founded considering that the social condition of Bandung City is increasingly heterogeneous where many migrants urbanize to find better livelihoods but cannot compete so that in the end, they commit criminal acts in an effort to maintain their livelihoods. Referring to this phenomenon, the implementation of Community Policing is directed at empowering community institutions in the community. However, this also has not given the expected results because the empowerment does not consider the background of the personnel empowered so that the implementation of the authority and attributes of the police deviates for personal gain.

The environmental conditions where the Polmas will be implemented will greatly influence the strategy of implementing the Community Policing. In each region, they will have their own characteristics when the Community Policing is implemented. As an example of the implementation of community policing in the city of Bandung, the application of community policing in urban elite areas and densely populated slums will certainly have differences in their implementation because they are matched with their respective problems and vulnerabilities.

The importance of reviewing environmental conditions in the context of implementing Polmas policies, in accordance with Tachjan's statement (2008: 38), namely that there are four important variables that must be considered in implementing public policy. The four variables are:

1. Idealized policy, namely the patterns of ideal interaction that they have defined in the wisdom that is trying to be induced;

2. Target Groups, namely those (people) who are most directly influenced by the wisdom and who must adopt patterns of interaction as expected by policymakers;

3. Implementing organization, namely implementing agencies or government bureaucratic units responsible for implementing policies;

4. Environmental factors, namely elements in the environment that influence or are influenced by the implementation of wisdom, such as cultural, social, economic and political aspects.

Adjustment of policy towards environmental conditions does not mean a change in wisdom, but a strategy for its implementation projected to answer the problems that exist in the environment. The implementation of the Community Policing was carried out in areas that had different conditions so that it was not changed the standard policy and rules for the 
Community Policing, but rather a strategy to implement the Community Policing that had to be attempted to accommodate the environmental conditions in which the Polmas were carried out.

\section{f. Response Analysis and Disposition of Implementing Apparatus}

Policing The concept of Community Policing, in general, has not been understood correctly and completely, both by the community and by the implementing members themselves. Inaccuracy in giving meaning to policing and understanding the philosophy behind the birth of the community policing (Polmas) movement eventually led to many deadlocks, even deviations in its implementation in the field. As explained by the results of an interview with KOMPOL Ari Purwanto which states that irregularities that often occur at the technical level generally come from community participants, such as irregularities in authority (conducting extortion) on behalf of security measures.

The fraud will have an impact on a policy that is applied so that sometimes it gets an unfavorable response and even rejection from the executor of the policy and from the goal of the policy itself. Disposition and response from all parties, especially the implementers of policy, must be thoroughly reviewed to ensure the attitude of the implementing policy towards the existence of the policy to be implemented. The tendency of disposition and direction of the implementing policy response is very important to be immediately known because it will directly involve the successful implementation of the policy itself. There must be synergy between all parties in the implementation of Community Policing in order to increase mutual understanding between the parties involved in Community Policing and to increase the understanding of these parties on the objectives of the Polmas itself. This is in line with the statement of Van Meter and Van Horn (1975: 472), stating that each component of the model discussed must be filtered through the perceptions of the implementers in the jurisdiction where the policy is implemented. The elements of the implementing response can affect the ability and willingness to carry out these policies, namely the implementers 'understanding of wisdom toward wisdom, the direction of the implementers' response to wisdom towards wisdom (acceptance, neutrality, rejection), and the intensity of the response.

\section{Factors that influence the Implementation of the Policy of Community Policing in Creating Public Security and Order in the City of Bandung}

\section{a. Inhibiting factor}

Based on the theory of Von Meter and Von Horn, of the 6 variables analyzed in the policy implementation policy of the Community there are several variables which are inhibiting factors, namely:

\section{Resources and Incentives}

These resources and incentives include Human Resources, financing resources, regulatory resources, and incentives for Polmas bearers. Human resources in the implementation of community policing in the city of Bandung at this time have not met the ideal standards for the implementation of community policing in accordance with expectations, both human 
resources from the police and human resources from the community. HR from the Police who were assigned to Community Police in the city of Bandung was mostly HR who was almost entering retirement with declining productivity. While the human resources from the most active community in FKPM are also not chosen citizens, only citizens who do not have much work and have more free time, this also shows enthusiasm or community support has not been maximized towards the implementation of Community Policing.

After the researcher conducted interviews with several informants as related parties in the implementation of Community Policing as explained by the Respondent who stated that:

... in general the Bhabinkamtibmas that are included in the implementation of the Community Policing are on average old, of course, this is an obstacle in achieving the objectives of the Community Policing because the implementation phase is too rigid so it is not in accordance with the habits of the community. In addition, the knowledge related to community policing by Bhabinkamtibmas is not well understood, so it is not uncommon for Bhabinkamtibmas to behave passively and wait for reports or complaints from the public.

After the researcher conducted interviews with several informants as related parties in the implementation of Community Policing as explained by the informant stating that:

...in the implementation of the Community Policing there is actually no funding specifically for visiting or conducting activities such as training, therefore the implementation is often stagnant. So far, funding for the implementation of community policing has come from internal sources that have taken from other programs so that the sources are very limited.

Based on the results of the informant's answer above, it shows that the problem of financing resources and the availability of costs for operational activities of community policing officers have not received serious attention. The minimal attention to the issue of financing indicates that the parties concerned with the Polmas have not been as clean and maximal in implementing the Polmas policy. Such minimal attention has had a big contribution to the lack of maximum implementation of community policing in the city of Bandung.

From the results of the interviews, it was shown that the implementation of community policing policies needed regular and continuous socialization because until now there were still many people who were not aware of the existence of the Polmas so that understanding of Community Policing was very limited. The lack of understanding of existing regulations is not an issue of the content of existing regulations but is caused by the intensity of socialization that must be increased. If summarized the inhibiting factors for the implementation of Polmas are as follows:

1. Quality of Human Resources that plays a role in low Polmas;

2. Inadequate funding resources;

3. Funding sources prone to fraud;

4. Lack of socialization of regulation on community policing.

The Ideal Model for Implementing the Policy of Community Policing in Creating Public Security and Order in the City of Bandung 
The implementation of Community Policing policies in creating security and public order in the city of Bandung is a policing strategy through study and analysis before it is implemented. According to Nurcholis (2006: 296) explained that the function of protection to the community is the efforts of the regional government to provide protection to the community so that order, peace, and security can be created in the community. This function is the most basic function of government because the result is a prerequisite for the work and running of government, community and development activities. The implementation of these government functions certainly requires good governance capabilities. In this context, Suradinata, (2013: 18) says:

Analysis of good governance not only uses SWOT analysis but also for Indonesia, in my opinion, can use ASOCA analysis, which stands for abilities, strengths, opportunities, culture, and agility. ASOCA's analysis adds elements of culture (culture) and agility (intelligence) as important elements in finding decision-making problem-solving strategies and can be developed in following changes, times and needs.

Such thinking arises from the background of the main essence in government management, namely to take strategic decisions by those who have government authorities and social organizations as decision-makers and those who carry out research both qualitatively and quantitatively after considering the results of ASOCA analysis, and other factors which requires the intelligence of a leader in decision making, and those who conduct research to provide the results of their research to those in need (Suradinata, 2013: 18). According to Suradinata (2013: 18), the terminology of ASOCA can be explained as follows:

\begin{abstract}
Ability: Ability comes from the word "capable" which means power (can, can) do something, can also people who are or are rich, have excess assets, the ability can also be interpreted ability, ability, ability themselves. Strength (strength, toughness): Toughness comes from the word "tough" which means it is difficult to beat, strong, reliable, very strong, tough and strong, strong. Toughness means strength, tenacity. Opportunities: Opportunities mean space for movement, both concrete and abstract and provide opportunities, possibilities for conducting useful activities for the need to achieve goals and programs. Culture: Culture means thoughts, culture, results, customs, and something about the culture that has developed (civilized, advanced) or something that becomes a habit that is difficult to change because agreements in certain environments are continuously maintained. With culture, people will advance and be modern and always live in their time. Agility: Intelligence comes from the word "smart" which means perfect development of reason, sharp mind, perfection in its growth, the perfection of mind, the sharpness of mind and intelligence. Ability alone is not enough, it must be with intelligence in managing thought, analyzing information to be made as a decision material.
\end{abstract}

According to Suradinata (2013: 19), the synergy of ASOCA elements is very important which can be grouped into internal and external strategic environments that can be made in the form of a matrix. The following is an ASOCA analysis matrix that is compatible with the Indonesian state or a large city of Bandung that is plural and has high social dynamics. 
Table 1. ASOCA's matrix for community policing analysis

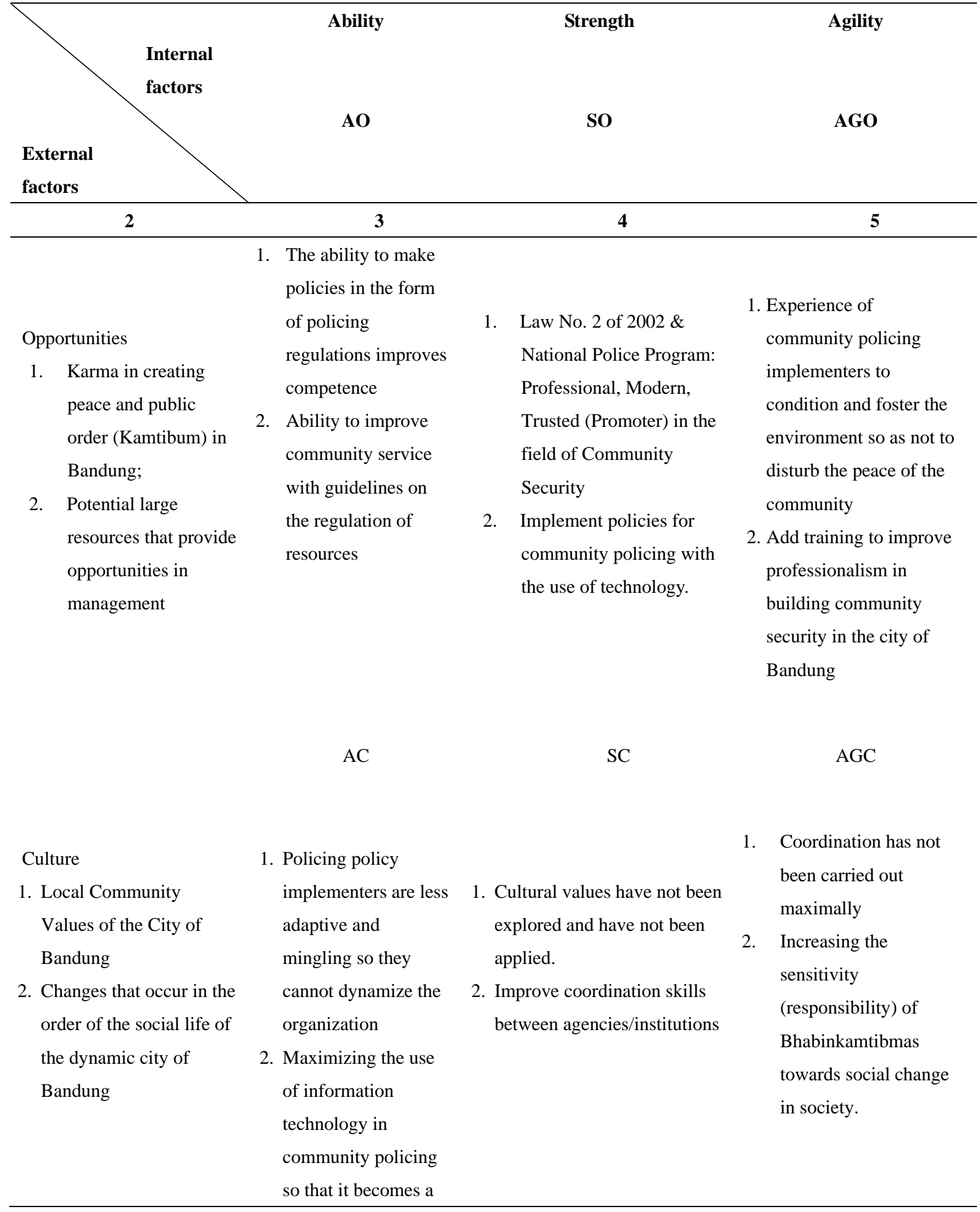




\begin{tabular}{llcc}
\hline $\begin{array}{l}\text { Internal } \\
\text { factors }\end{array}$ & Ability & Strength & Agility \\
External \\
factors
\end{tabular}

fast service culture.

Source: managed by author, 2019

The table above shows an eleven-box matrix that looks at the organization from internal organizational factors, namely, ability, strength, and agility and looks at external factors, namely opportunities, and culture. The other six boxes are actions that must be carried out by the organization when the internal factors of the organization are faced with external factors. (Suradinata, 2013: 20). Judging from internal factors there are factors of ability (ability), strength (strength), and agility (intelligence), here how to use the ability to take advantage of opportunities and face the demands of cultural change environment, how to use power to take advantage of opportunities and to be responsive to the influence of cultural change, and how to use intelligence to take advantage of opportunities and anticipate the effects of cultural change. With ASOCA Analysis, 6 (six) strategies can be identified that will be used in implementing community policing to improve security and public order. The six strategies are as follows:

1. The strategy of Ability-Opportunities (Ab-O)

a. Maximizing the ability to make policies in the form of policing regulations by increasing competence.

b. Ability to improve administration to provide community services with guidelines for resource regulation.

2. Strength-Opportunities (S-O) Strategy

a. Follow the law. 2002 and the National Police Chief's program as follows, professional, modern, trusted (promoter in the field of community security).

b. Implement policies for community policing with the use of technology.

3. Agility and Opportunities (Ag-O) Strategy

a. Bhabinkamtibmas has increased its ability to be able to foster the environment so that there is no disruption to community security.

b. Add training to improve the professionalism of community security in the city of Bandung.

4. Strength-Culture Strategy (S-C)

a. Maximizing the excavation of cultural values and applying them and supported by adequate information technology facilities. 
b. Improve coordination capabilities between agencies and institutions.

5. Ability-Culture Strategy (Ab-C)

a. Improving the knowledge of the implementor towards understanding local cultural capital so as to dynamize the organization.

b. Maximizing the use of information technology in fostering community policing.

6. Agility-Culture Strategy (A-C)

a. Increasing the sensitivity (responsibility) of Bhabinkamtibmas towards social change in society

b. Maximize coordination between institutions and communities.

Based on the ASOCA analysis related to the implementation of community policing policies in creating security and public order in the city of Bandung, there are 2 strategies that must be taken, as follows:

1. Strength-Opportunities (S-O), namely increasing the ability of Bhabinkamtibmas in implementing Community Policing with policing using information technology.

2. Strength-Culture (S-C), maximizing and using intelligence to empower local culture (empowerment local culture) so that Bhabinkamtibmas can overcome social changes in society.

Based on the results of ASOCA's analysis, the researcher made a model that is able to accommodate the potentials in each region and anticipate the dynamics of the community that are influenced by technological advances and globalization so that the policy of community policing can be carried out effectively. Hence the author calls the new model of Community Policing Policy Implementation, namely: OK PRAPTO Model.

1. Orientation on competence $(\mathrm{O})$ is to ensure the implementer of the policy Community policing has the ability in accordance with the needs of the situation and conditions in each task area or an effort to improve the ability of those who play a role in community policing through education and training especially in terms of mastery of the socio-cultural conditions of the area of work.

2. Coordination (K), namely the ability of the managers who are able to maintain good communication within the internal task force and with external parties, both institutions and communities involved in implementing Community Policing.

3. Community Empowerment $(\mathrm{P})$, namely the ability of the implementers to carry out the excavation of the local culture from the community's social conditions that are able to support the implementation of effective policing policies.

4. Responsive (R), is an awareness of tasks that must be taken seriously. Sharp sensitivity in responding to the various things it faces and understanding of the meaning of responsibility that must be borne in carrying out Polmas policies in the area of development. 


\section{Macrothink}

5. Actualization (A), namely the ability of the policy implementers of the Polmas to carry out behaviors that are in accordance with their roles and responsibilities in accordance with the culture of independence and social responsibility in their respective environments and carry out tasks in accordance with the potential areas of their duties.

6. Professional (P), namely the attitude of the Polmas executor who has capabilities that are in accordance with the functions needed in the implementation of the Community Police as well as the work carried out with a high ability and cling to the moral values that direct and underlie the actions he performs.

7. Transparency (T), namely the principle of openness of the police towards the community/community and other parties related to efforts to ensure security, orderly and peaceful, in order to jointly understand the problem, not suspect each other and be able to foster mutual trust other;

8. Orientation on service $(\mathrm{O})$, that the implementation of the task of the Polmas utilizes the development of information technology so that it further improves services as community rights that must be fulfilled by police members.

\section{Closing}

Based on the explanation of the research in the previous chapter, the researcher draws conclusions in response to the questions contained in the formulation of the problem as follows:

1. Referring to Von Horn's Von Meter public policy Implementation model, empirical facts were found, namely: 1) Variables on supporting factors: implementing commitment, communication, implementing attitude, and socio-economic and political conditions; 2) Variables on inhibiting factors: lack of clarity on rules of standards, limited resources, less empowering local culture;

2. ASOCA's analysis of empirical facts there are two things that must be taken in implementing Community Policing policies through, 1) Strategy Strenght - Opportunities uses strength by taking advantage of opportunities: increasing the ability of Bhabinkamtibmas to implement Community Policing by optimizing Information Technology. 2) Strenght-Culture strategies maximize intelligence to empower local culture;

3. The ideal model of policing that is able to accommodate the potentials in the city of Bandung and can anticipate the dynamics of changing a society that is influenced by the progress of Information and Technology in the Globalization era so that the policy of community policing can run effectively so that it can use the OK PRAPTO Model.

\section{Glossary}

Polri : National Police of Republic of Indonesia

Polmas : Community Policing

Kamtibmas : Security and Public Order 
Kamtibum : : Security and Public Order

Polrestabes : : Big City Resort Police

Bhabinkamtibmas : The guiding policeman for peace and public order

\section{Reference}

Dunn, N. W. (2000). Pengantar Analisis Kebijakan Publik. Terjemahan Samodra Wibawa dkk, Yogyakarta: Gajah Mada University Press.

Edward III, G. C. (1980). Implementing Public Policy, Congressional Quarterly Inc, USA.

Grindle, M. S. (1980). Politics and Policy Implementation in the Third World, Princeton University.

Hill, M., \& Peter, H. (2002). Implementing Publik Policy, London: SAGE Publications Ltd.

Lubans, A. V., \& Edgar, M. J. (1979). Policing By Objectives A Handbook for Improving Police Management. Social Development Corporation Hartford, Connecticut.

Santoso, T., \& dan Eva, A. S. (2001). Kriminologi. Jakarta. TB Borneo.

Sharkansky, I. (1973). Public Administration: Policy-making in Government Agencies. $2^{\text {nd }}$ Edition. Ran McNally. Chicago.

Suradinata, E. (2013). Analisis Kepemimpinan Strategi Pengambilan, Jatinangor: Alqaprint.

Tachjan, H. (2008). Implementasi Kebijakan Publik, Bandung : AIPI.

Van Meter, D. S., \& Van Horn, C. E. (1975). The Policy Implementation Process. A Conceptual Framework. Administration and Society, 6(4). London: Sage Publications, Inc.

\section{Copyright Disclaimer}

Copyright for this article is retained by the author(s), with first publication rights granted to the journal.

This is an open-access article distributed under the terms and conditions of the Creative Commons Attribution license (http://creativecommons.org/licenses/by/4.0/). 